\title{
Kemoterapi Alan Hastalarda Venöz Dolgunluk ve Görünürlüğü Sağlayıcı Teknikler
}

\author{
Şüle BIYIK BAYRAM 國 ${ }^{1}$, Handan EREN [i] $^{2}$, Nurcan ÇALIŞKAN 國 ${ }^{3}$
}

\begin{abstract}
ÖZ
Periferal yoldan uzun süre verilen kemoterapi tedavileri damarların epitel tabakasına zarar vermektedir. Bu durum birçok komplikasyona yol açarak, damarların dolgunluğunu ve görünürlüğünü etkilemekte, hemşirelerin ise periferal intravenöz kateter uygulaması sırasında zorluk yaşamasına neden olmaktadır. Bu zorluklar hastaların işlem sırasında ağrı, anksiyete yaşamasına ve tedavinin gecikmesine neden olabilmektedir. Bu durumları önlemek için periferal kateter uygulamasındaki ilk aşama, ven görünürlüğü ve venöz dolgunluğunun sağlanmasıdır. Bunun için turnike uygulaması veya tansiyon aletinin manşonunun kola takılarak şişirilmesi, kolun kalp seviyesinin aşă̆ısında tutulması, izometrik egzersiz uygulamas1, parmak ucuyla vene vurulması, venin sivazlanması ve lokal sicak uygulama yapılmasi, ultrason ve kızıl ötesi ışınların kullanımı şeklinde farklı teknikler bulunmaktadır. Kliniklerde turnike, kolun kalp seviyesinin aşağısında tutulması ve veni sıvazlama tekniklerinin sıklıkla kullanıldığı görülmektedir. Diğer yöntemlerin kullanımına ilişkin çalışmalar yapılmakta ve kemoterapi alan hastalarda etkisi ve kullanım şekli belirtilmektedir. Hemşirelerin bu yöntemleri bilmesi ve kemoterapi alan hasta grupları gibi damarsal yapısı bozulmuş hastalara kullanabilmesi yaşayacakları bu güçlükleri ve komplikasyonları en aza indirecektir. Bu nedenle bu makalenin amacı kemoterapi alan hastalarda ven görünürlüğ̈̈ ve venöz dolgunluğu sağlayıcı teknikler hakkında kanıta dayalı bilgiler vererek, hemşirelerin bu konuya dikkatini çekmek ve bu bilgilerin uygulamaya aktarılmasını sağlamaktır.
\end{abstract}

Anahtar Kelimeler: Hemşirelik bakımı; intravenöz; kateterizasyon; kemoterapi.

\section{Vein Visibility and Venous Fullness Providing Techniques in Patients with Chemotherapy}

\begin{abstract}
Chemotherapy treatments are given for a long time through the peripheral intravenous damage the epithelial layer of the vessels. This situation causes many complications, affects the fullness and visibility of the vessels, and causes nurses to experience difficulties during peripheral intravenous catheter application. These difficulties may cause patients to experience pain, anxiety, and delay treatment. To prevent these conditions, the first step in peripheral catheter application is to provide vein visibility and venous fullness. For this purpose, there are different techniques such as tourniquet application or swelling of the sphygmomanometer by inserting the arm into the arm, keeping the arm below the heart level, isometric exercise application, tapping the vein with the fingertip, applying the vein and performing local hot application, using ultrasound and infrared rays. In clinics, it is seen that tourniquet, keeping the arm below the heart level and vein tapping techniques are frequently used. Studies on the use of other techniques are being conducted and the effect and technique of use are specified in patient groups receiving chemotherapy. Nurses' knowledge of these techniques and their use in patients with vascular structure such as patient groups receiving chemotherapy will minimize these difficulties and complications. For this reason, the purpose of this article is to provide evidence-based information about the techniques that provide vein visibility and venous fullness in patients receiving chemotherapy, to attract nurses' attention to this issue and to ensure that this information is put into practice.
\end{abstract}

Keywords: Nursing care; intravenous; catheterization; chemotherapy.

1 Karadeniz Teknik Üniversitesi, Sağlık Bilimleri Fakültesi, Hemşirelik Bölümü, Trabzon, Türkiye

2 Yalova Üniversitesi, Sağlık Bilimleri Fakültesi, Hemşirelik Bölümü, Yalova, Türkiye

3 Gazi Üniversitesi, Sağlık Bilimleri Fakültesi, Hemşirelik Bölümü, Ankara, Türkiye

Sorumlu Yazar / Corresponding Author: Şule BIYIK BAYRAM, e-mail: sulebiyik@gmail.com Geliş Tarihi / Received: 05.05.2020, Kabul Tarihi / Accepted: 16.03.2021 


\section{GIRIŞ}

Hastaneye yatan bireylerin yaklaşık \%80'ine ilaç veya sıvı tedavisi için periferal intravenöz kateter (PIVK) yerleştirilmektedir. Amerika'da her yıl 330 milyon hastaya PİVK takılmaktadır $(1,2)$. Ülkemizde ise kaç hastaya PIVK uygulandığına dair bir veri bulunmamakla birlikte bir üniversite hastanesinde 2012 yılında satın alınan kateter sayısının 242,450 olduğu belirtilmiştir (3). Hemşireler tarafindan sıkça uygulanan ve invaziv bir işlem olan PİK uygulaması başarılı ve tek seferde gerçekleştirilmesi, uzman bilgisini gerektirmekte ve bu sayede birçok komplikasyon önlenebilmektedir (4). Hemşirelerin işleme yönelik bilgi ve beceri düzeyi yeterli olmasına rağmen PIVK yerleştirme işlemi bazen zorlaşmaktadır. Özellikle intravenöz kemoterapi tedavisi işlemini zorlaştıran bu faktörlerden biri de PIVK tedavisidir (5). Çünkü kemoterapi ilaçları toksik özelliktedir. Toksisite özelliklerine göre bu ilaçlar vezikan, irritan ve non-vezikan olmak üzere üç gruba ayrılmaktadır. Vezikan ilaçlar hem DNA'ya bağlanarak hem de bağlanmadan etki edebilmekte, damara verildiğinde ilacın damar dışına sızmasına neden olmaktadır. İrritan olanlar ise; damar dışına çıktığında kateterin giriş bölgesinde ya da ven boyunca ağriya, yumuşak doku yaralanmalarına ve ülsere neden olabilmektedir. Ayrıca bu ilaçların ozmolaritesi (350 mOsm/L) damar içi sıvı ozmolaritesinden (275-295 $\mathrm{mOsm} / \mathrm{L}$ ) daha yoğundur. $\mathrm{Bu}$ farklılık damar endotel tabakasını bozarak, damarın hassas ve kaygan olmasına neden olmaktadır (6).

Kemoterapi ilaçları flebit, infiltrasyon, ekstravazasyon, tromboflebit ve septisemi gibi komplikasyonlara neden olmaktadır (7). Bu komplikasyonlar ven boyunca ağrı, kızarıklık, ilerleyen dönemlerde ülserasyon ve nekrozlara yol açmakta, sempatik sinir sitemini uyarmakta, bu durumda damarların kasılarak dolgunluğunu ve görünürlüğünü azalmaktadır. Bu durum PİVK yerleştirme işlemini zorlaştırmakta, bu sebeple tekrarlayan girişimlere neden olmaktadır. Ayrıca bu durum bakım maliyetini ve hemşirenin iş yükünü arttırmaktadır. Bu nedenlerle kemoterapi tedavisi alan hastalarda uygun veni bulmak ve venöz dolgunluğu sağlamak güçleşmektedir. $\mathrm{Bu}$ durum hastanın anksiyete ve ağrısının artmasına, hemşirenin işlemi tekrarlamasına, işlem için ayırdığ 1 sürenin uzamasına neden olmaktadır. $(5,8)$. Bu nedenle kateterin tek seferde yerleştirilebilmesi, hastanın ağrı ve anksiyetesinin azaltılabilmesi için işleme başlarken ilk yapılması gereken damar görünürlüğünün ve venöz dolgunluğun sağlanmasıdır.

Venöz dolgunluk; venlerin görülebilmesi ve palpe edilebilmesi olarak tanımlanmaktadır. Bu nedenle venöz dönüşün hızlanması ve vazodilatasyonun sağlanması gerekir (9). Bazı damarlar kolayca palpe edilip, görünebilmekte; bazıları ise ne görünmekte ne de palpe edilebilmektedir. Venler hem görünürlük hem de palpe edilebilirlik durumuna göre derecelendirilmektedir $(5,8,10)$. Literatürde bu derecelendirme için kullanılan örnekler tablo $1(5,8)$ ve tablo 2 'de $(10)$ verilmiştir. Bu derecelendirmelerin kullanılması, hemşirelere hasta takibi açısından kolaylık sağlayabilmektedir. Böylece hastanın tedavisi ile damarsal yapısı arasındaki ilişki izlenebilir.
Tablo 1. Ven Derecelendirme Skalas1 $(5,8)$

\begin{tabular}{|l|l|}
\hline 1.derece & Venler hiç görülmüyor ve palpe edilmiyor. \\
\hline 2.derece & Venler görülüyor ancak palpe edilmiyor. \\
\hline 3.derece & Venler zor görülüyor ve palpe edilebiliyor. \\
\hline 4.derece & Venler görülüyor ve palpe edilebiliyor. \\
\hline 5.derece & Venler çok iyi görülüyor ve palpe edilebiliyor. \\
\hline
\end{tabular}

Tablo 2. Ven Derecelendirme Aracı (10)

\begin{tabular}{|l|l|}
\hline Çok iyi & $\begin{array}{l}\text { Ven turnike uygulandığında kolay görülüyor ve } \\
\text { kolay palpe ediliyor. }\end{array}$ \\
\hline İyi & Ven küçük, kırılgan ve zor palpe ediliyor. \\
\hline Kötü & Venin görünürlügü ve palpasyonu yeterli değil. \\
\hline
\end{tabular}

\section{İntravenöz Kemoterapi Tedavisinde Ven Görünürlüğünü ve Venöz Dolgunluğunu Artırmada Kullanılan Teknikler}

Venlerin görünür ve palpe edilebilir olması ve venöz dolgunluğun sağlanması için çeşitli teknikler bulunmaktadır (11). Bu teknikler; turnike uygulaması veya tansiyon aletinin manşonunun kola takılarak şişirilmesi, kolun kalp seviyesinin aşağısında tutulması, izometrik egzersiz uygulaması, parmak ucuyla vene vurulması, venin sivazlanması, lokal sicak uygulama yapılması, ultrason ve kızıl ötesi 1şınların kullanımı şeklinde sıralanabilmektedir $(4,9,11,12)$. Bu teknikler, vene girişi kolaylaştırarak işılemin başarısını arttırmakta, tekrarlayan vene giriş uygulamasını azaltmakta, tekrarlı girişimlerin hastada oluşturduğu travmayı ve rahatsızlığı önleyebilmektedir (13-15). Literatürde bu şekilde birçok teknik belirtilmiş olsa da kliniklerde en çok turnike uygulamasının kullanıldığı gözlenmektedir. Periferal intravenöz kateter uygulaması yapılan farklı hasta gruplarının olması turnike uygulamasının yetersiz kalmasina veya kateter uygulaması sonrası komplikasyonların ortaya çıkmasına neden olabilmektedir $(16,17)$. Ancak turnike uygulaması dışında diğer tekniklerin kullanımına ilişkin literatürdeki bilgiler sinırlidır $(5,8,13,18)$. Bu nedenle bu derleme komplikasyonların önlenmesi, venöz dolgunluğu ve görünürlüğü sağlayacak farklı yöntemlerin nasıl kullanılacağına ilişkin kanıt düzeyi yüksek çalışmalar incelenerek tartışılmıştır.

\section{Teknik: Turnike ve tansiyon aleti uygulaması}

PIVK öncesi venöz dolgunluğu sağlayan ve en çok kullanılan teknik turnike uygulamasıdır. Kauçuk, silikon ve ayarlanabilir türde olanları bulunmaktadır (11).Turnike, belirlenen venin 10-15 cm üzerinden veya antekübital fossanın üzerinden arter dolaşımını engellemeyecek şekilde uygulanmalı ve turnikenin arter dolaşımına engel olup olmadığını belirlemek için radial nabız kontrol edilmelidir. Cildin yaralanmasını önlemek için turnike mutlaka kıyafet üzerinden uygulanmalı ya da turnikenin cilde temas eden kısmının altına bir havlu koyulması önerilmektedir $(4,11)$. Turnikenin basınç süresi ise literatürde değişiklik gösterse de bu sürenin maksimum 60 saniye olması gerektiği de belirtilmektedir $(18,19)$.

Turnike yerine tansiyon aleti manşonun kullanımı da venöz dolgunluğu sağlamaktadır (4). İki tekniğin karşılaştırıldığ 1 çalışmalarda ise farklı sonuçlar olduğu görülmektedir $(21,22)$. Xiong ve ark. (20) 50 sağlıklı bireyle yürüttüğü prospektif randomize olmayan çalışmada, $60 \mathrm{mmHg}$ basınç ile manşon uygulamasının 
ven çapında $1.15 \mathrm{~mm}$, kesit alanında ise $8.3 \mathrm{~mm}^{2}$ genişleme sağladığı, $30 \mathrm{mmHg}$ ve $120 \mathrm{mmHg}$ basınçla manşon uygulamasına ve turnike uygulamasına göre ven çapına daha fazla etki ettiği belirtilmiştir. Nelson ve ark. (19) tarafından yürütülen randomize kontrollü bir çalışmada ise ultrason yardımı ile gerçekleştirilen PIVK yerleştirme işleminde tansiyon aleti manşonu ile turnike kullanımının venin derinliği ve çapında anlamlı farklılık yaratmadığı ancak turnike kullanımının tansiyon aleti manşonu kullanımına göre ven dilatasyonunda daha etkili olduğu belirtilmiştir. Bu uygulamada, manşonun basinc1 değişiklik gösterse de bireyin normal diyastolik basıncının hemen altındaki seviyeye kadar (4) veya sistolik değer $100 \mathrm{mmHg}$ olacak şekilde şişirilmesi önerilmektedir (12).

Tansiyon aleti manşonu kullanımı turnikeye göre ciltte daha az travmaya neden olmaktadır (4). Bu nedenle ven yapıları hassas olan yaşlı hastalarda ve antikoagülan veya kortikostreoid kullananlarda turnike uygulaması yerine tansiyon aleti manşonu kullanılması önerilmektedir $(21,22)$. Ayrıca plastik ve kauçuk tipte turnikenin kullanılması enfeksiyona ve sinir zedelenmesine neden olmaktadır (23). Çalışma sonuçlarında, turnike veya tansiyon aleti manşonun ven görünürlügüünü ve venöz dolgunluğunu artırdığı, dolayısıyla kemoterapi tedavisi alan hastalarda PIVK öncesinde kullanılabileceği ve tansiyon aleti manşonu kullanımının özellikle ilerleyen kürlerle birlikte damar yapısı bozulan hastalarda daha güvenli olacağı belirtilmiştir $(12,21,22)$.

2. Teknik: Kolun kalp seviyesinin altında tutulması, vensıvazlama ve vene vurma uygulaması

Venöz dolgunluğu sağlayan diğer bir teknik ise, kolu kalp seviyesinden aşağıda tutarak yerçekimi etkisi ile venöz dönüşü yavaşlatmaktır (11). Yerçekimi etkisi venöz dönüşü yavaşlatmakta böylece venöz kan volümünü ve üst ekstremite venlerinin basıncını artırmaktadır. Venöz basınç arttığında ise ven dolgunluğu da artmaktadır (12). Literatürde kolun kalp seviyesinin altında tutulmasına ilişkin deneysel çalışma bulgularına rastlanmamakla birlikte ven görünürlüğü sağlamada kullanılabileceği belirtilmektedir (10).

Vene girilmek istenen alanın altında distalden proksimale doğru ekstremiteyi sıvazlama hareketi ve vene vurulmas1 da venöz dolgunluğunu sağlayan diğer bir tekniktir. Ancak bu teknik ağnılı olabilmektedir. Yaşı bireylerde dolaşım yavaşladığından ve damar yapısının elastik özelliği kaybolduğundan ve ayrıca kemoterapi tedavisi alan hastalarda tekrarlayan kürler nedeniyle ven yapıs1 bozulduğundan bu işlemden kaçınılması gerektiği belirtilmektedir $(9,11)$.

\section{Teknik: İzometrik el egzersizi uygulaması}

Ven dolgunluğunu sağlamak için elin açıp kapanması hareketi izometrik aktivite ile muskarinik reseptörleri uyararak derin venlerdeki kanın yüzeyel venlere pompalanmasını sağlamaktadır. Böylece kan akış hızı ve damar gerginliği artmakta ve distal venler genişlemektedir (12,24). El içine top alınarak, el dinamometresi veya el ergometresi kullanılarak uygulanabilen bu teknikte, kasılan kasın içine kan akımı azalmakta ve oksijen ihtiyacı artmaktadır. Bu durumda kasta biriken metabolitler kan akımını hızlandırmakta ve dolayısıyla venlerin dolgunlaşmasına sebep olmaktadır (24). Özkaraman ve Yesilbakan Usta (15) tarafindan yapılan bir çalışmada, intravenöz kemoterapi tedavisi alan hastalara el yayı ile günde yirmi dakika olmak üzere haftada beş gün süren izometrik el sıkma egzersizinin brakiyal ven akım hızını artırdığ istatistiksel açıdan anlamlı düzeyde olmadığı belirtilmiştir. Eren ve Çalışkan (13) tarafından yapılan çalışmada da benzer sonuçlar elde edilmiştir. Çalışmada kemoterapi tedavisi alan 45 hastaya $10 \mathrm{kez}$ avuç açma kapama işlemi yaptırıldığında ven görünürlüğünün artırdığı, uygun veni bulma ve başarılı kateter yerleştirme süresinin azaldığı ancak bunun istatistiksel açıdan anlamlı farklılık yaratmadığı görülmüştür. Periferal intravenöz kateter yerleştirme öncesinde izometrik el egzersizinin ven görünürlüğünü sağladığı ancak yeterli düzeyde sağlanması için bu egzersizin minimum kaç kez yapılacağı ile ilgili bir çalışmaya rastlanmamıştır.

\section{Teknik: Lokal sicak uygulama}

Yapılan çalışmalarda bu yöntemin etkili olduğu belirtilse de $(5,8,10)$ Bıyık Bayram ve ark. (25) tarafindan yapılan bir çalışmada kliniklerde yeterince uygulanmadığı görülmektedir. Lokal sıcak uygulama, $\alpha_{2}$ adrenerjikvazokonstrüktör etkiyi ortadan kaldırarak pasif vazodilatasyon, beta reseptörlerini uyararak aktif vazodilatasyon sağlamaktadır (3). Venlerin orta tabakasındaki düz kaslar sempatik sinir sistemi tarafindan inerve edilmekte ve bu sistem kontrolü altında kasılıp gevşeyerek damar çapının değişmesine neden olmaktadır (24). Lokal sıcak uygulama yapıldığında bölgedeki damarlarda vazodilatasyon ile kan akımı artmakta ve venöz dolgunluk sağlanmaktadır. Kateter uygulanacak bölgeye 10-15 dakika 1lı uygulama yapılması vazodilatasyonu ve kan akımını artırmakta, yüzeyel kan damarlarının dolmasını sağlamaktadır $(8,9,11)$. Kateter uygulama öncesinde kontraendike değilse hastanın sicak duş alması da önerilebilmektedir (11).

Literatürde vazodilatasyon için deri sıcaklığının $39-42^{\circ} \mathrm{C}$ olması gerektiği ve bunun için kullanılan lokal sıcak pedin sıcaklığının $52^{\circ} \mathrm{C}$ olması ve 10 veya 15 dakika süre ile deri üzerinde bekletilmesi gerektiği belirtilmiştir $(8,14)$. Yamagami ve ark. (26) tarafından yapılan başka bir çalışmada ise $40 \pm 2^{\circ} \mathrm{C}$ 'lik lokal sıcak pedin minimum 5 dakika süre ile deri yüzeyinde bekletilmesinin vazodilatasyonu sağlamada yeterli olduğu belirtilmiştir. Tokizava ve ark. (27) yaptığı çalışmada ise en az 5 dakika yapılan sıcak uygulamanın ven görünürlügüüü arttırdığ1 da belirtilmiştir. Yamagami ve ark. (21) tarafindan yapılan başka bir çalışmada ise 30 saniyelik turnike uygulamasından önce 15 dakika sicak uygulama yapılmasının damar kesit alanının $10.1 \mathrm{~mm}^{2}$, yalnızca turnike uygulamasında ise $7.9 \mathrm{~mm}^{2}$ olduğu ve bu farkın istatistiksel açıdan anlamlı olduğu belirtilmiştir.

Kemoterapi alan hastalarda yapılan çalışmalarda lokal sicak uygulamanın, lokal sicak ped, aquatermik ped ve jel ile sağlandığı görülmektedir. Çalışma yöntemlerinde ise lokal sicak uygulama turnike uygulamasından önce yapılmamıştır. Çalışma sonuçlarında lokal sıcak uygulamanın ven görünürlüğünü ve palpasyonunu anlamlı derecede artırdığı, işlemin daha kısa sürede ve tek seferde yapılabildiği, vene giriş başarı oranının arttığı, tekrarlı işlemleri önlediği, hastanın ağrı ve anksiyetesini azalttığı, memnuniyetini arttırdığı, hemşirenin işlem için geçirdiği süre ve iş yükünün azaldığı belirtilmiştir $(5,8,10,14)$. 


\section{Teknik: Ultrason ve kızıl ötesi ışınlar}

Günümüzde teknolojinin getirdiği donanımlardan faydalanarak venlerin görünürlüğü için dolgunluğun sağlamasının gerekli olmadığını da görmekteyiz. Venleri görünür kılan ultrasonografi (USG) ve kızıl ötesi 1şınlar, ven dolgunluğunu sağlamadan bizleri yönlendirmektedirler (28). Ultrason cihazlarındaki prop ile venler sıkıştırılarak monitöre yansıtılmakta böylece venin çap1 ve kateterin ven içerisindeki ilerleyişi izlenebilmektedir (29). Yapılan çalışmalarda USG ile PIVK uygulamasının, kateter girişim başarı şansını artırdığ 1 , hastanın hastanede kalma süresini azalttığı, bakım maliyetini düşürdüğü, hasta memnuniyetini artırdığ 1 , santral kateter ihtiyacını ve kateter girişiminde harcanan süreyi azalttığ 1 belirtilmektedir (30-33). Gregg ve ark. tarafindan (33) travma, cerrahi ve kardiyoloji kliniklerdeki hastalarda USG kullanılarak PIVK uygulamasının yapıldığı bir çalışmada ilk girişimin başarısının \%71 olduğu belirlenmiştir. Aynı şekilde Stolz ve ark. (31) yaptığı çalışmada da ultrason yönteminin ven girişinin ilk seferde başarı şansının \%70 olduğu belirtilmiştir. Ayrıca periferal intravenöz kateter yerleşim işlemi zor olan hastalarda ultrason kullanımının incelendiği meta analiz çalışmasında, ultrason kullanımının PIVK yerleştirme başarısını artırdığ belirtilmiştir. $\mathrm{Bu}$ nedenle USG'nin özellikle intravenöz kemoterapi tedavisi alan hastalarda kullanılmasının hastayı yormadan işlemdeki başarı şansını arttıracağı düşünülmektedir.

Kızıl ötesi 1şınlar ise hemoglobinin 1şı̆̆ özelliğinden yararlanarak bireyin cildi üzerinde ven boyunca görüntü sağlamakta, böylece uygulayıcının hissedemediği damarı görmesine yardımcı olmaktadır. Cihazların birçoğu hastaya temas etmeden, bölgeden yaklaşık $18 \mathrm{~cm}$ uzaklıktan kullanılabilmektedir $(13,34)$. Literatürde, bu cihazların hastalarda PIVK yerleştirme işleminde kullanımına yönelik birçok çalışma bulunmaktadır. $\mathrm{Bu}$ çalışmalar genellikle, yenidoğan, pediyatri, acil ünitelerine başvuran hastalarla yürütülmüş ve uygun venin belirlenmesinde etkili olduğu görülmüştür (34-36). Chiao ve ark. (37) tarafından kızıl ötesi 1şınlar ile yapılan randomize kontrollü çalışmada özellikle obez, cilt rengi koyu olan bireylerde kolaylık sağladığ1 belirtilmiştir. Kemoterapi tedavisi alan hastalarla yürütülen çalışmalara bakıldığında ise; Ramer ve ark. (38) yaşları 1 ile 21 arasında olan 53 hasta ile yürüttüğü randomize çalışmada, kullanılan damar görüntüleme cihazının işlem süresini anlamlı derecede kısalttığı, ancak girişim sayısında istatistiksel açıdan anlamlı bir fark yaratmadığı görülmüştür. Kaddoum ve ark. (39) 0-18 yaş arası kanser tanısı ile izlenen 146 hastada yürüttüğü randomize kontrollü araştırmada, hastalara anestezi uzmanları tarafından PIVK yerleştirildiği; ten rengi koyu olan, ven derecesi düşük olan hastalarda tek seferde başarılı girişim oranının damar görüntüleme cihazında daha yüksek olduğu ancak bu farklılığın istatistiksel açıdan anlamlı olmadığı görülmüştür. Eren ve Çalışkan'ın (13), kemoterapi tedavisi almakta olan erişkin hastalarla yürüttüğü randomize kontrollü çalışmada, damar görüntüleme cihazının başarılı kateter yerleştirme süresini istatistiksel açıdan anlamlı düzeyde kısalttığ işlemden memnuniyet düzeyini ise artırdığı görülmüştür.
Çalışmalardan da görüldüğü üzere, cihazların farklı hasta grupları ve farklı ven derecesinde olan hastalarda kullanıldığı, kateter yerleştirme süresine olumlu etkileri olduğu ve ven derecesi düşük olan hastalarda kullanımı önerilmiştir.

\section{SONUC VE ÖNERILER}

Hemşirelik uygulamalarının kanıta dayalı olması bakım kalitesini ve bakım sonuçlarını iyileştirmekte, klinik uygulamalarda ve hasta bakım sonuçlarında fark yaratmakta, bakımı standardize etmektedir (40). Bu nedenle periferal intravenöz kateter uygulaması öncesinde de venöz dolgunluğun ve görünürlüğü sağlayan bu tekniklerin bilinmesi hemşirelerin bakım kalitesini arttırmakta ve hastaların memnuniyetini arttırmaktadır. $\mathrm{Bu}$ derlemede yapılan son çalışma sonuçlarına dayalı olarak periferal kateter uygulaması öncesinde venöz dolgunluk ve ven görünürlüğünün sağlanması için yapılabilecek hemşirelik girişimleri ele alınmış ve kemoterapi alan hastalarda yapılan uygulama sonuçları değerlendirilmiştir.

Sonuç olarak, kemoterapi tedavisi alan bireylerde PİK uygulamasında hemşire ve birey açısından güçlükler yaşandığı görülmektedir. Periferal intravenöz kateter uygulaması öncesi ven görünürlüğünün ve venöz dolgunluğunun sağlanması uygulamanın hem birey hem de hemşire için kolay olmasını sağlamaktadır. Bu nedenle ven dolgunluğunu sağlayan ve yaygın olarak kullanılan turnike uygulaması dışında da farklı teknikler kullanılabilir. $\mathrm{Bu}$ derleme sonunda, hemşirelerin bu tür tekniklerden haberdar olması, uygulamaları esnasında kullanması ve bu teknikler ile ilgili çalışmalar yapması önerilmektedir.

Yazarların Katkıları: Fikir/Kavram: Ş.B.B., N.Ç.; Tasarım: Ş.B.B., N.Ç.; Literatür Taraması: Ş.B.B., H.E.; Makale Yazımı: Ş.B.B., H.E., N.Ç.; Eleştirel İnceleme: Ş.B.B., H.E., N.Ç.

\section{KAYNAKLAR}

1. Vizcarra C, Cassutt C, Corbitt N, Richardson D, Runde D, Stafford, K. Recommendations for improving safety practices with short peripheral catheters. Journal of Infusion Nursing. 2014; 37(2): 121-4.

2. Keleekai NL, Schuster CA, Murray CL, King MA, Stahl BR, Labrozzi, L. et al. Improving nurses' peripheral intravenous catheter insertion knowledge, confidence, and skillsusing a simulation-based blended learning program: A randomized trial. Simulation in Healthcare. 2016;11(6): 376.

3. Bıyık Bayram Ş. İntravenöz kateter girişimi öncesi lokal sicak uygulamanın hastanın ağrı, anksiyete ve memnuniyeti üzerine etkisi. [Yüksek lisans tezi]. Ankara: Gazi Üniversitesi Sağlık Bilimleri Enstitüsü; 2013.

4. Uzun Ş. İntravenöz sıvı tedavisi. Atabek Aştı $T$, Karadağ A, editör (ler). Hemşirelik esasları bilgiden uygulamaya: kavramlar-ilkeler-beceriler. İstanbul: Akademi basın ve yayıncılık, 2019. p.700-30.

5. Fink RM, Hjort E, Wenger B, Cook PF. Cunningham M, Orf A, et al. The impact of dry versus moist heat on peripheral catheterinsertion in a hematology- 
oncology out patient population. Oncology Nursing Forum. 2009; 36(4): 198-204.

6. Doellman D, Hadaway L, BoweGeddes, LA, LeDonne J, PapkeO'Donnell L, Pettit J, et al. Infiltration and extravasation. The Art and Science of Infusion Nursing. 2009; 32(4): 203-11.

7. Özkaraman A, Yesilbakan OU. Periferal intravenöz kemoterapi uygulamasına yönelik hemşirelik yönetimi. Osmangazi Journal of Medicine. 2015; 36(1): 27-34.

8. Lenhardt R., Seybold T, Kimberger O, Stoiser B, Sessler DI. Local warming and insertion of peripheral venous cannulas: single blinded prospective randomised controlled trial and single blinded randomised cross over trial. British Medical Journal. 2002; 325(7361): 409-503.

9. Potter PA, Perry AG. Fundamentals of Nursing. 8th ed. Mosby Inc. St Louis Missouri 2013.

10. Kaur M, Kaur S, Firuza DP. Effect of 'moist heat therapy' on the visibility and palpability of peripheral veins before peripheral venous cannulation of patients under going chemotherapy. Nursing and Midwifery Research Journal. 2011; 7: 99-105.

11. Berman, AJ, Snyder S, Kozier B, Erb G. Kozier Erb's fundamentals of nursing: concepts, process, and practice 10th ed. Pearson Prentice Hall: Upper Saddle River; USA, 2016.

12. Roberge RJ. Venodilatation techniques to enhance venepuncture and intravenous cannulation. The Journal of Emergency Medicine. 2004; 27(1): 69-73.

13. Eren H. Kemoterapi alan hastalarda damar görüntüleme cihazı ve avuç açma kapama tekniğinin ven görünürlüğüne etkisi. [Doktora tezi]. Ankara: Gazi Üniversitesi Sağlık Bilimleri Enstitüsü; 2018.

14. Bıyık Bayram Ş, Çalışkan N. Effects of local heat application before intravenous catheter insertion in chemotherapy patients. Journal of Clinical Nursing. 2016; 25(11-12): 1740-7.

15. Özkaraman A, Yesilbalkan OU. Effect of isometric hand grip exercises on blood flow and placement of IV catheters for administration of chemotherapy. Clinical Journal of Oncology Nursing. 2016; 20(2): 55-9.

16. Bertoglio S, Van Boxtel T, Goossens GA, Dougherty L, Furtwangler R, Lennan E, et al. Improving out comes of short peripheral vascular access in oncology and chemotherapy administration. The Journal of Vascular Access. 2017; 18(2): 89-96.

17. Parreira P, Serambeque B, Costa PS, Mónico LS, Oliveira V, Sousa LB, et al. Impact of an innovative securement dressing andt ourniquet in peripheral intravenous catheter-related complication sand contamination: An interventional study. International journal of environmental research and public health. 2019; 16(18): 3301-13.

18. Sasaki S, Murakami N, Matsumura Y, Ichimura M, Mori M. Relationship between tourniquet pressure and a cross-sectionarea of superficial vein of forearm. ActaMed. Okayama. 2012; 66(1): 67-71.

19. Nelson D, Jeanmonod R, Jeanmonod D. Randomizedtrial of tourniquet vs blood pressure cuff or target veindilation in ultrasound-guided peripheral intravenous access. The American Journal of Emergency Medicine. 2014; 32(7): 761-4.

20. Xiong J, Zhan P, Ding Y, Mu F, Sun Y, Wang H, et al. Which, tourniquet or inflation of blood pressure cuff, can dilate peripheral vein adequately for intravenous access. Biomedical Journal of Scientific and Technical Research. 2019; 20(1): 14775-84.

21. Yamagami $Y$, Tomita $K$, Tsujimoto $T$, Inoue $T$. Tourniquet application after local forearm warming to improve venodilation for peripheral intravenous cannulation in young and middle-age dadults: A single-blind prospective randomized controlled trial. International Journal of Nursing Studies. 2017; 72: 17.

22. Cantor-Peled G, Halak M, Ovadia-Blechman Z. Peripheral vein locating techniques. Imaging in Medicine. 2016; 8(3): 83-8.

23. Mattox EA. Complications of peripheral venous access devices: prevention, detection, and recovery strategies. Crit Care Nurse. 2017; 37(2): 1-14.

24. Arınc1 K, Elhan A. Anatomi.6. Baskı. Ankara: Güneş Tip Kitabevleri; 2016.

25. Bıyık Bayram Ş, Gülnar E, Akbaytürk N, Çalışkan N. Kemoterapi alan hastalarda infiltrasyon ve flebit görülme sıklığı ve risk faktörleri: gözlemsel prospektif çalışma. 6.Uluslararası, 17. Ulusal hemşirelik kongresi, Aralık 2019, Ankara.

26. Yamagami Y, Tsujimoto T, Inoue T. How long should local warming for venodilation be used for peripheral intravenous cannulation? A prospective observational study. International Journal of Nursing Studies. 2018; 79: 52-7.

27. Tokizawa Y, Tsujimoto $\mathrm{T}$, Inoue $\mathrm{T}$. Duration of venodilation for peripheral intravenous cannulation, as induced by a thermal stimulus on the forearm. Biological Research for Nursing. 2017; 19(2): 206-12.

28. İsmailoğlu EG, Zaybak A, Akarca FK, Kıyan S. The effect of the use of ultrasound in the success of peripheral venous catheterisation. International Emergency Nursing. 2015; 23(2): 89-93.

29. Hebbard PD, Flinn P. Intravascular catheters-an ultrasoun dimaging based observational study of position andf unction. Anaesthesia and intensive care. 2017; 45(4): 499-502.

30. EL-Shafey EM, Tammam TF. Ultrasonographyguided peripheral intravenous access: regular techique versus seldinger tecnique in patients with difficult vascular Access. European Journal of General Medicine. 2012; 9(4): 216-22.

31. Stolz LA, Cappa AR, Minckler MR, Stolz U, Wyatt RG, Binger CW, et al. Prospective evaluation of the learning curve for ultrasound-guided peripheral intravenous catheter placement. The Journal of Vascular Access. 2016; 17(4): 366-70.

32. Khan MS, Sabnis VB, Phansalkar DS, Prasad SP, Karnam AHF, Hasan A. Use of ultrasound in peripheral venous catheterization in adult emergency and critical care units. Anaesthesia Pain \& Intensive Care. 2015; 19(3): 303-10.

33. Gregg SC, Murthi SB, Sisley AC, Stein DM, Scalea, TM. Ultrasound-guided peripheral intravenous access in the intensive care unit. Journal of Critical Care. 2010; 25(3): 514-9. 
34. Aulagnier J, Hoc C, Mathieu E, Dreyfus JF, Fischler M. Guen, ML. Efficacyof accu vein to facilitate peripheral intravenous placement in adults presenting to an emergency department: a randomized clinical trial. Academic Emergency Medicine.2014; 21: 85863.

35. Fumagalli S, Torricelli G, Massi M, Calvani S, Boni S, Roberts AT. et al. Effects of a new device to quide venous puncture in elderly critically ill patients: results of a pilot randomized study. Aging Clin Exp Res. 2017; 29: 335-9.

36. Haile D, Suominen PK. Technologies in pediatric vascular access: have we improved success rate in peripheral vein cannulation?. Acta Anaesthesiologica Scandinavica. 2017; 61(7): 710-3.

37. Chiao FB, Resta-Flarer F, Lesser J, Ng J, Ganz A, Pino-Luey $\mathrm{D}$ et al. Vein visualization: Patient characteristic factor sand efficacy of a new infrared vein finder technology. British Journal of Anaesthesia. 2013; 110(6): 966-71.

38. Ramer L, Hunt P, Ortega E, Knowlton J, Briggs R, Hirokawa S. Effect of intravenous (IV) assistive device (veinWiewer) on IV Access attempts, procedural time, and patient and nurse satisfaction. Journal of Pediatric Oncology Nursing. 2016; 33(4): 273-81.

39. Kaddoum RN, Anghelescu DL, Parish ME, Wright $\mathrm{BB}$, Trujillo $\mathrm{L}, \mathrm{Wu} \mathrm{J}$, et al. A randomized controlled trial comparing the AccuVein AV300 device to standard insertion technique for intravenous cannulation of anesthetized children. Paediatr Anaesth. 2012; 22(9): 884-9.

40. Stevens K. The impact of evidence-based practice in nursing and the next bigideas. The Online Journal of Issues in Nursing, 2013; 18(2): 4. 